\title{
What does the dominant eye dominate? A brief and somewhat contentious review
}

\author{
ALISTAIR P. MAPP, HIROSHI ONO, and RAPHAEL BARBEITO \\ York University, Toronto, Ontario, Canada
}

\begin{abstract}
We examine a set of implicit and explicit claims about the concept of eye dominance that have been made over the years and note that the new literature on eye dominance does not reflect the old literature from the first half of the last century. We argue that the visual and oculomotor function of the dominant eye-defined by such criteria as asymmetry in acuity, rivalry, or sighting — remains unknown and that the usefulness of the concept for understanding its function is yet to be determined. We suggest that the sighting-dominant eye is the eye used for monocular tasks and has no unique functional role in vision.
\end{abstract}

Interest in eye dominance has a long and rich history. Coren and Porac (1975) published an annotated bibliography of 235 articles on this topic. Their search began with the original article on eye dominance by Porta (1593) and extended to 1975. Recently, we searched the 1975-2002 PsychINFO database and found an additional 340 articles. (This paper is not intended to be a review of the entire ocular dominance literature. For reviews of early studies on eye dominance, see Barbeito [1979], Porac \& Coren [1976], and Wade [1998]). Despite this extensive literature, however, the function of eye dominance remains a theoretical puzzle. Given the recent contributions to this literature and the renewed interest in the nature and neural basis of dominance and suppression in vision (e.g., Blake, 2003; Blake \& Logothetis, 2002; Howard \& Rogers, 2002), it is timely to examine the status of a set of claims about eye dominance that have been made either implicitly or explicitly over the years. Before doing so, however, we emphasize that several criteria by which eye dominance is to be defined have been identified in the literature (e.g., Coren \& Kaplan, 1973; Howard, 2002; Warren \& Clark, 1938), and which eye has been identified as the dominant one by the different criteria has not necessarily been the same. To simplify this paper, we will restrict our discussion to the three criteria described by Howard (2002), which were postulated on the basis of

This research was supported by a York University Contract Faculty Research Grant (to A.P.M.) and Grant A0296 from the Natural Sciences and Engineering Research Council of Canada (to H.O.). The authors thank C. Aro and O. Espiritu for their help in conducting the ear preference experiments to confirm our predictions, L. Lillakas for preparing the figure and editing the paper, and J. D. Crawford, E. Gonzalez, C. D. Green, P. Grove, L. R. Harris, I. P. Howard, N. Khokhotva, R. Kohly, M. J. Steinbach, H. Wilson, and J. Wolfe for their helpful comments and discussions on an earlier version of this paper. Correspondence concerning this article should be addressed to H. Ono, Centre for Vision Research, York University, Toronto, ON, M3J 1P3 Canada (e-mail: hono@yorku.ca).
Coren and Kaplan's finding discussed in Claim 2, below. The three defining criteria are

(a) the eye with better visual acuity, contrast sensitivity, or other measure of visual functioning..., (b) the eye in which a rivaling stimulus is most often dominant, and (c) the eye used for sighting when, for instance, one looks at a distant object through a ring held in both hands at arm's length with both eyes open. [p. 295; the order in which the three criteria is listed was changed to parallel our discussion]

With these three criteria, we will (1) comment on several claims about eye dominance, with particular emphasis on those pertaining to the eye identified as the sightingdominant one, and (2) make a suggestion about the function of the sighting-dominant eye. We will illustrate our suggestion with a gedanken, or thought experiment.

\section{Claim 1: Eye Dominance Is Related to Handedness or Hemispheric Dominance}

The assumption underlying this claim is that all types of dominance, including eye dominance defined by any criteria, result from a single causal factor-namely, hemispheric specialization. Given the differences in the neural connections between the limbs and the brain and those between the eyes and the brain, however, it is unlikely that the hemispheric specialization responsible for the different types of dominance is the same. The afference from a limb and the efference to the same limb are associated with one hemisphere of the brain. In contrast, the afference from one eye is projected to both hemispheres, and the efference to the muscles of one eye originates in different hemispheres, depending on the desired direction of the eye movement. That is, the brain is lateralized for the hands or legs, but not for the eyes. The dominant hand, for example, is stronger and more dexterous than the nondominant hand, but as a rule, there is no such pronounced asymmetry for the pair of eyes. It was proposed, some time ago, that the dominant eye is unrelated to cerebral laterality (e.g., M. M. Clark, 1957; Warren \& 
Clark, 1938; White, 1969). Consistent with this, an overwhelming preponderance of studies fails to show a clear relationship between handedness and "eyedness" (e.g., Annett, 1999; M. M. Clark, 1957; Coren \& Kaplan, 1973; Gronwall \& Sampson, 1971; McManus, Porac, Bryden, \& Boucher, 1999; Merrell, 1957; Papousek \& Schulter, 1999; Pointer, 2001; Porac \& Coren, 1975a; Snyder \& Snyder, 1928).

\section{Claim 2: There Is "a Single Dominant Eye" for Each Person}

The assumption underlying this claim is that eye dominance is a single, unitary concept and the three criteria listed in the introduction are the tools by which this concept is measured. The results from a factor analysis study, however, cast doubt on this assumption. Coren and Kaplan (1973), using a variety of eye dominance tests (13 tests given to 54 normal observers), identified three statistically independent factors underpinning the results of the various tests-namely, (1) the eye with the better acuity, (2) the eye that predominates during binocular rivalry, and (3) the eye that is used in sighting. They found that most of the differences in the test results were accounted for by sighting dominance. Consistent with the finding that the three factors are independent, an overwhelming preponderance of studies have shown that eye dominance measured with one criterion does not correlate well with that measured with the other criteria (e.g., Coons \& Mathias, 1928; Coren \& Kaplan, 1973; Cuff, 1931; Downey, 1933; Fink, 1938; Gahagan, 1933; Gronwall \& Sampson, 1971; Hildreth, 1949; Merrell, 1957; Mills, 1925; Pointer, 2001; Porac \& Coren, 1976; Snyder \& Snyder, 1928; Walls, 1951; Warren \& Clark, 1938; Washburn, Faison, \& Scott, 1934; cf. Crovitz, 1961; Friedlander, 1971; Money, 1972; Porac, Whitford, \& Coren, 1976; Schoen \& Scofield, 1935).

The prevailing view in the literature, however, seems to be that there is a single dominant eye for each person. For example, the motivation for two recent fMRI studies was, in part, to find the neural basis of a "unitary dominant eye" (Menon, Ogawa, Strupp, \& Ugurbil, 1997; Rombouts, Barkhof, Sprenger, Valk, \& Scheltens, 1996). Rombouts et al. reported that for "right-eye-dominant observers," monocular stimulation of the right eye activated a greater proportion of the primary visual cortex than did stimulation of the left eye. No such asymmetry was found for "left-eye-dominant observers." Likewise, Menon et al. noted "a slight preponderance of right eye dominant pixels" (p. 2785) in their group of 4 "righteyed" and 1 "left-eyed" observers. These claims are consistent with the idea that there are small asymmetries in the inputs from the two eyes for some observers, but they do not make a convincing link with the concept of a unitary dominant eye. The neural response they uncovered may be related to the sighting-dominant eye, not to a unitary dominant eye, since dominance was measured with the Porta Sighting Test. In a subsequent psychophysical study, Khan and Crawford (2001) were more explicit in their assumption about a unitary dominant eye, since they discussed possible "gating" of the visual input by the sighting-dominanteye and speculated about the role of the sighting-dominant eye in "oculocentric organization" or "egocentric visual reference." Before the concept of eye dominance can be considered as unitary, persuasive arguments explaining the lack of correlation between dominances measured with the three criteria must be presented. To our knowledge, no such studies exist.

Although it seems clear from the large body of literature already available that the eye identified as the dominant one by the different criteria does not represent a unitary concept for the general population, it may for some subpopulations. Applying reductio ad absurdum to the concept of eye dominance, we expect that for observers completely blind in one eye or for those with extreme amblyopia, the nonimpaired eye would be identified as the dominant one with any of the three criteria. Consider, for example, an observer with amblyopia. The nonamblyopic eye, having better acuity, would suppress the amblyopic eye, at least to some degree. It is also reasonable to expect that the nonamblyopic eye would be used for sighting and, therefore, this observer (or this subpopulation of observers) would have a dominant eye that fits the suggestion that there is a single dominant eye for each person. However, the usefulness of this idea in describing the visual or oculomotor processes for such a subpopulation or for the normal population is yet to be established.

The literature on amblyopia is relatively large (see Ciuffreda, Levi, \& Selenow, 1992, Howard, 2002, and Levi, 1991, for discussions and reviews of the different types of amblyopia) and although the term ocular dominance is used clinically in this context, there is no indication that the concept of a dominant eye is a unitary one for normal observers. For example, in a recent paper by Schröder, Fries, Roelfsema, Singer, and Engel (2002), the term ocular dominance was used to describe the difference in the percentage of cortical cells that respond to the two eyes. The study clearly addressed the issue of differences in cortical response produced by stimulation of the normal eye and the amblyopic eye, and it was clearly not intended to address the issue of whether the concept of eye dominance is a unitary one or not. There was no reason for Schröder et al. to do so, however, since it is probably immaterial whether the "ocular dominance" they described is related to the sighting-dominant eye, for example. In fact, the terms dominant eye or nondominant eye are not used in the paper; the eyes are referred to as the normal (or nonamblyopic eye) and the amblyopic eye. Indeed, there is no advantage in calling the normal eye the dominant eye and the amblyopic eye the nondominant eye. Moreover, understanding the consequences of stimulation of the two eyes found in this literature does not require a unitary concept of eye dominance. Whether understanding the different consequences would lead to a single unitary concept of eye dominance for normal observers is yet to be determined. 


\section{Claim 3: For a Given Test There Is a Dominant Eye}

If we were to define eye dominance as being whatever an eye dominance test tests, then by definition, this claim is correct. However, the pertinent issue here is whether different tests within a particular criterion of dominance identify the same eye as the dominant one and whether the identified eye plays a special role in visual and/or oculomotor functions.

Criterion A: Dominance defined by asymmetry. The discussion of amblyopia above is particularly pertinent to eye dominance defined by asymmetry. If the acuity or contrast sensitivity of members of the general population were to be measured repeatedly, it is likely that asymmetries would be found for most observers. However, as was discussed in Claim 2, the role of an asymmetry in acuity or contrast sensitivity is yet to be determined for the general population. There are studies in which oculomotor asymmetries have been examined during vergence (B. Clark, 1936), during version (Moiseeva, Slavutskaya, \& Shul'govskii, 2000), and during eye movements that require both vergence and version (Barbeito, Tam, \& Ono, 1986; Pickwell, 1972), but the correlation between these asymmetries and acuity asymmetry was not examined. If different asymmetries do not correlate, asymmetry dominance as a single unified concept becomes questionable.

Criterion B: Dominance defined by rivalry. This seemingly straightforward criterion of eye dominance turns out to be, upon examination, not so straightforward. The percentage of time that one eye's view predominates when rivalrous stimuli are viewed is easily measured when the stimuli are small, but not when they are large. That is, when the stimuli are large, there is rivalry between different parts, and what "dominates" at any given moment is not restricted to the input from one eye. Moreover, rivalries between forms, contours, and colors may be brought about by different mechanisms. Consistent with this, J. M. Wolfe (personal communication, December 3, 2001) found repeatable patterns of local "dominance" for the input of one eye over the other when dominance was measured at multiple locations in the visual field. However, these patterns of dominance were different for different tasks (pointing, form rivalry, and color rivalry).

The fact that a large stimulus cannot give a straightforward index of eye dominance is not the only difficulty in defining the dominant eye with the criterion of rivalry. The percentage of time that one eye sees a small stimulus or the percentage of time for local dominance or local fusion can be controlled by the contours, the contrast, or the temporal properties of the competing stimuli (e.g., Howard \& Rogers, 2002; Levelt, 1968; Ono, Komoda, \& Mueller, 1971; Wolfe, 1983, 1986a). For a given set of binocular stimuli, one can partition the variance of dominance into that due to stimulus variables and that due to individual differences (van Kruysbergen, 1995). ${ }^{1}$ The viability of the concept of rivalry dominance depends on the correlation between this individual dif- ference and other perceptual variables. We are unaware of any studies that have examined rivalry dominance within this framework. Until such studies are done, the usefulness of the concept of eye dominance, as defined by the second criterion, is difficult to evaluate.

It has been hypothesized that suppression of the amblyopic eye, particularly in the case of strabismic amblyopia, develops to avoid double vision (e.g., von Noorden, 1990) and that a similar process operates for normal observers (Coren \& Duckman, 1975; Porac \& Coren, 1975b). There is evidence, however, to suggest that strabismic suppression differs from normal rivalry suppression (see Howard, 2002). For example, it has been shown that these types of suppression (1) differ in strength (Holopigian, Blake, \& Greenwald, 1988) and (2) are elicited by different types of stimuli (Schor, 1977; Smith, Levi, Manny, Harwerth, \& White, 1985). For single vision, Porta mentioned the possible role of normal rivalry suppression as early as 1593 (see Wade, 1998), and since then several others have noted its possible role (e.g., Asher, 1953; Charnwood, 1954; Ono, Angus, \& Gregor, 1977; Verhoeff, 1935; Wolfe, 1986b). Whether invoking the concept of eye dominance enhances this hypothesis, however, is questionable. The fact that there is rivalry between competing stimuli in the two eyes of "normal" observers indicates that suppression is not limited to one eye. The question becomes whether the portion of the eye that suppresses the input from the corresponding portion of the other eye for a greater percent of the time has a special visual or oculomotor function.

Criterion C: Dominance defined by sighting. The sighting-dominant eye comes closest to fulfilling the claim that there is a dominant eye for a given test or even a set of tests. Sighting dominance has been tested by having observers view a target through a hole in a card (Card Test; Durand \& Gould, 1910) or through a hole at the narrow end of a cone (Miles ABC Test; Miles, 1929). It has also been tested by having observers position a near stimulus (e.g., a pencil or a finger) so that it appears collinear with a more distant stimulus (Porta Test; Porta, 1593; see Wade, 1998). Each of these tests provides a clear operational definition of sighting dominance, and each demonstrates that observers show a consistent preference for one eye over the other in these viewing situations. Each sighting clearly identifies which eye is used to perform the task, and the test-retest reliability is high (Miles, 1928, 1929; Porac \& Coren, 1976). Moreover, the correlation among the scores from the three sighting tests is high (Coren \& Kaplan, 1973; Gronwall \& Sampson, 1971). This suggests that there is a sighting-dominant eye for each person tested with a set of sighting dominance tests.

However, there is evidence that the eye identified as the sighting-dominant one is dependent on (1) the observer's knowledge about the task (Miles, 1929), (2) the direction that the card is moved in the Card Test (Ono \& Barbeito, 1982), (3) gaze angle (Khan \& Crawford, 2001), and (4) the hand used in certain situations (Carey, 
2001). These observations that the eye that "dominates" is situation or task specific can be construed as violations of the requirement of the sighting test. In the history of testing which eye is used for sighting, experimenters have attempted to remove all biases that might influence which eye was identified as the dominant one (e.g., handedness). Within this framework, moving the card from one side, or asymmetrical gaze angle, or using only one hand can all be construed as producing an undesirable measurement artifact. Whether the change in the identified eye should be interpreted as an artifact of the measurement technique or a change in the sightingdominant eye depends on the hypothesized function of the sighting-dominant eye. A hypothesized function of the measured sighting-dominant eye that accommodates both interpretations is offered later.

\section{Claim 4: The Sighting-Dominant Eye Is the Egocenter}

We now focus on the sighting-dominant eye. Dominance as defined by this criterion has been shown to be reliable (Miles, 1928, 1929; Porac \& Coren, 1976), at least within a given viewing situation or stimulus arrangement, and also accounts for most of the variance when a battery of eye dominance tests is used (Coren \& Kaplan, 1973). The focus here is on the claim that the sighting-dominant eye is the reference point for visual direction (Khan \& Crawford, 2001; Parson, 1924; Porac \& Coren, 1981; Rubin \& Walls, 1969; Sheard, 1926; Walls, 1951). This claim continues to be made despite an abundance of ev- idence in the literature to show that it is inappropriate. We will discuss the inappropriateness by referring to what is predicted in a simple $2 \times 2$ experiment. In the experiment, we suggest that a ring be placed midway between a fixated stimulus and the face, as was suggested by Howard and Rogers (1995) and used by Khan and Crawford. The observer's task is to point with an unseen hand (e.g., under a table) to the apparent location of the ring and the fixation target. In one condition, the ring is placed on the visual axis of the dominant eye, and in another condition, it is placed on that of the nondominant eye. Each condition has two subconditions: In one subcondition, binocular fixation is on the far stimulus, and in the other, it is on the ring. This suggested experiment is identical to one conducted by Ono and Barbeito (1982), except for the use of a ring instead of the hole in the Card Test. A recent discussion of the results appeared in Mapp and Ono (1999) under the heading "visual direction task confusion revisited."

What is predicted and illustrated in Figure 1 has been known since the time of Ptolemy, circa 100-170 A.D. (see Howard \& Wade, 1996). The figure shows that objects on the visual axis appear on the common axis, a line passing through the intersection of the visual axes and the bridge of the nose. This phenomenon was observed, for example, by Alhazen (1083/1989), Hering (1879/1942), Le Conte (1871), and Wells (1792) and was discussed recently by Howard (1996), Mapp and Ono (1999), Mapp, Ono, and Howard (2002), Ono, Lillakas, and Mapp (2003), and Ono, Mapp, and Howard (2002). The figure

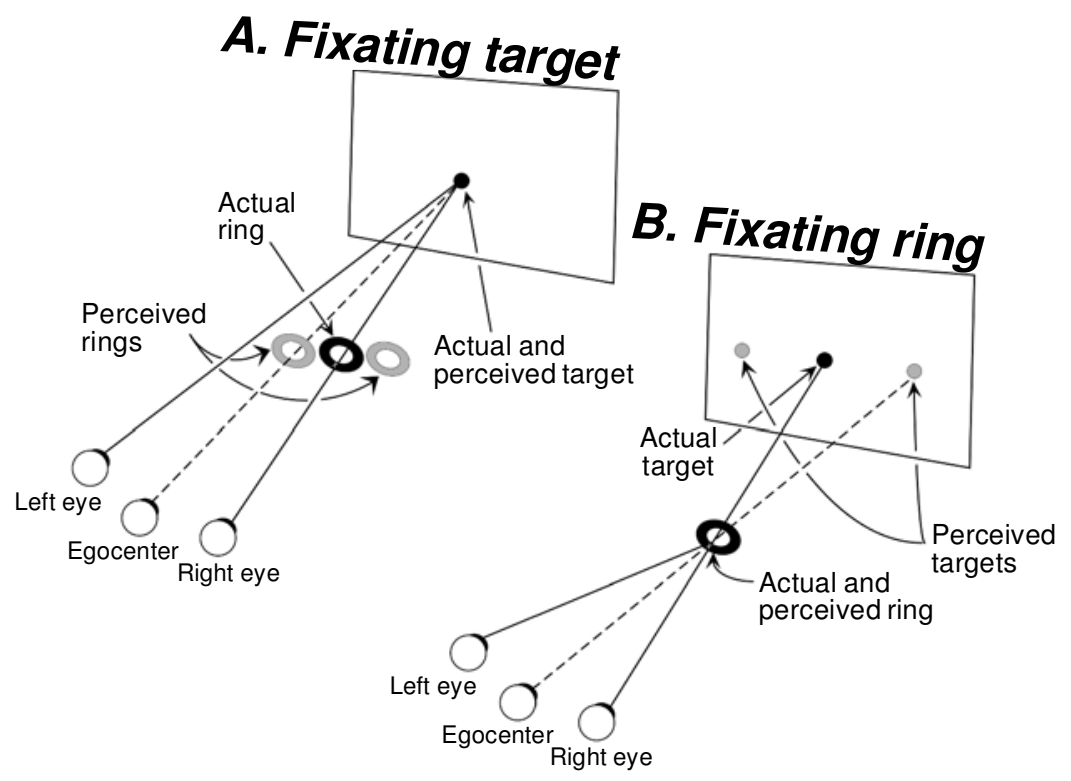

Figure 1. Illustration of stimuli on a visual axis appearing on the common axis. The two stimuli on the visual axis of the right eye are seen on the common axis (dashed lines). When fixation changes from the far stimulus (A) to the ring (B), the top of the common axis shifts to the right. The ring is seen as double when the far stimulus is fixated, and the stimulus is seen as double when the ring is fixated (see Barbeito \& Simpson, 1991; Mapp \& Ono, 1999; Ono \& Barbeito, 1982). 
illustrates that the ring appears on the common axis when fixation is on the distant target or on the ring. Although not explicitly illustrated, this holds true regardless of whether the ring is on the visual axis of the dominant eye or that of the nondominant eye (see Barbeito \& Simpson, 1991). What is illustrated indicates that (1) the positions of both the sighting-dominant eye and the nondominant eye are used in processing visual direction, since the location of the common axis is determined by the binocular eye position, and (2) the visual input from neither of the eyes is suppressed, since both diplopic images of the nonfixated stimulus are seen. Also, the figure and the literature indicate that the suggestion that the sighting-dominant eye serves as the "egocentric visual reference point" (Khan \& Crawford, 2001) is unwarranted. Although the measured location of the reference point deviates from the midpoint between the eyes and the direction of the deviation correlates with the measured sighting-dominant eye, it never coincides with either of the eyes (Barbeito, 1981; Porac \& Coren, 1986; cf. Walls, 1951). The reference point has been given many names-for example, the binoculus, the egocenter, the double eye, the projection center, the center of visual direction, and the cyclopean eye.

Moreover, the claim that the sighting-dominant eye serves as the egocenter is contrary to the idea that the eyes, both as sensors and as motor units, operate not as two separate organs, but as two halves of a single organ (Hering, 1868/1977). ${ }^{2}$ For the eyes as sensors, Hering's idea is reasonable, since the brain uses information from both eyes to localize visual stimuli. For the eyes as motor units, the idea is also reasonable, since unitary commands are issued to both eyes, as summarized in what he termed equal innervations to the two eyes. The details of Hering's law of identical visual direction or of his law of equal innervation are not at issue here. (For recent discussions of the eyes as sensors, see, e.g., Erkelens \& van de Grind, 1994, and Ono, Shimono, Saida, \& Ujike, 2000; for the eyes as motor units, see Enright, 1992, and Saida, Ono, \& Mapp, 2001.) Rather, the issue is that in order for the concept of a sighting-dominant eye to be useful in egocentric localization tasks, it must be incorporated into the generally accepted view of how the eyes work together to process visual direction or depth and/or how they move. Without compelling data to argue otherwise, the default interpretation of the sighting-dominant eye is that it plays no unique role in such localization tasks. Since it reverses as easily as changing the angle of gaze (Khan \& Crawford, 2001) or as a function of the direction from which the card is moved in the Card Test (Ono \& Barbeito, 1982), it may well be analogous to the ease with which ear preference reversed in our telephone experiment described below.

\section{Suggestion: The Sighting-Dominant Eye Is the Eye Used for Monocular Tasks and Has No Unique Functional Role in Vision}

We suggest here that the eye identified as the dominant one in a sighting task is determined by nothing more than the constraint of the sighting task that only one eye be used and the ease or the habit of using a particular eye to perform the task (Barbeito, 1981; Miles, 1928; Ono \& Barbeito, 1982). We also suggest that other than being the "preferred" eye in some viewing situations, the sightingdominant eye has no special role for visual or oculomotor processes for the normal population.

To illustrate this view, we present the following gedanken, or thought experiment, to demonstrate what we mean by our suggestion that sighting dominance is nothing more than a preference for a particular eye. ${ }^{3}$ Imagine measuring ear preference, or "dominance," as defined operationally by the ear to which a telephone is placed. Imagine further that the participants are required to either (1) pick up the telephone with one hand at a time and to say "hello" into the receiver or (2) dial a number, retrieve a voice mail, and write down the message. We predict that the hand used to pick up the telephone will determine the ear to which the phone is placed in both (1) and (2), and we further predict that the hand used in (2) will not be the one typically used for writing. We further predict that for each individual within each condition, the same pattern would be exhibited over repeated trialsthat is, "ear" preference would be shown to be highly reliable. Our interpretation of such a result is that ear preference is situation specific and that the preferred ear is based on the constraint that only one ear can be used and on a habit acquired from the ease of placing the telephone over the ear on the same side as the hand holding the receiver.

We contend that looking into a telescope, a microscope, or a peephole is also explainable in a similar manner; Miles (1928) and Barbeito (1981) have argued that the eye identified as the sighting-dominant one in a given test situation is determined by the constraint that forces monocular sighting and the habit or ease of using that eye. A habit in a particular stimulus situation would produce a reliable response, whereas a different task in a different stimulus situation would produce a situationspecific response. Presumably, a habit is formed because it is easier to move the head or a tube in the direction of the eye that is closer to the sighting-dominant eye. These findings and this interpretation are consistent with the view that the reliability of the sighting-dominant eye is due to the constraint that forces monocular sighting and the habit or ease of using that eye.

Indeed, if the constraints of sighting with only one eye are removed, the results of sighting tests are startlingly different. When an adult is asked to perform the Card Test with the hole covered or is asked to perform the Porta Sighting Test with hand unseen, the covered hole or the unseen hand is place, on average, collinear with respect to the target and a point someplace between the two eyes (Barbeito, 1981). Consistent with this finding, young children cannot sight with one eye and learn to do so around age 4 (Barbeito, 1983; Church, 1966; Dengis et al., 1996). When young children are asked to look through a tube, they place the tube right between the two eyes, the phenomenon known as a cyclops effect. When 
adults are asked to perform the same task while an electronic shutter blocks the visual target as the tube is approaching the face, they also show the cyclops effect (Dengis, Simpson, Steinbach, \& Ono, 1998).

\section{Conclusion}

The purpose of this paper was to provide a brief review of some of the literature that is relevant to recent claims about dominance that have appeared repeatedly in the literature. To date, none of the common claims (either implicit or explicit) about the visual or oculomotor significance of a "dominant" eye has been supported by empirical evidence, and the conclusions reached in the first half of the last century still seem applicable. Warren and Clark (1938) concluded that "laterality of eye functioning ... is not an indication of any cerebral dominance" and that "eye dominance as a single unitary factor does not exist" (p. 302). Both conclusions still seem correct. Moreover, the visual or oculomotor significance of different "dominant" eyes measured with different methods is yet to be established. Regarding the most frequently measured eye dominance-that is, sighting dominance - the literature shows that if one is forced to use one eye, either by nature (i.e., amblyopia or strabismus) or by the task at hand (i.e., sighting a distant target through a narrow tube), an adult or an older child will do so (e.g., Miles, 1930). The role that this eye may play in visual and oculomotor processes, however, remains obscure. Thus, it appears that there has been little advancement in our understanding of eye dominance since Miles (1930) concluded that "the significance of optical dominance is not yet fully evident, although it appears generally demonstrable as a habit" (p. 427).

\section{REFERENCES}

Alhazen, I. (1989). Book of optics. In The optics of Ibn al-Haytham (A. I. Sabra, Trans.). London: Warburg Institute. (Original work published 1083)

AnNetT, M. (1999). Eye dominance in families predicted by the right shift theory. Laterality, 4, 167-172.

AsHer, H. (1953). Suppression theory of binocular vision. British Journal of Ophthalmology, 37, 37-49.

Barbeito, R. (1979). Ocular dominance: An explanation based on sighting behavior. Unpublished doctoral dissertation, York University, Toronto.

BARBEITO, R. (1981). Ocular dominance: An explanation based on processing of visual direction in tests of sighting dominance. Vision Research, 21, 855-860.

Barbeito, R. (1983). Sighting from the cyclopean eye: The cyclops effect in preschool children. Perception \& Psychophysics, 33, 561-564.

Barbeito, R., Levi, D., Klein, S., Loshin, D., \& Ono, H. (1985). Stereo-deficients and stereo-blind cannot make utroculor discriminations. Vision Research, 25, 1345-1348.

Barbeito, R., \& Simpson, T. L. (1991). The relationship between eye position and egocentric visual direction. Perception \& Psychophysics, 50, 373-382.

Barbeito, R., TAM, W. J., \& ONo. H. (1986). Two factors affecting saccadic amplitude during vergence: The location of the cyclopean eye and a left-right bias. Ophthalmology\& Physiological Optics, 6, 201205.

BLAKE, R. (2003). Reconciling rival interpretations of binocular rivalry. In L. Harris \& M. Jenkin (Eds.), Levels of perception (pp. 101-126). New York: Springer-Verlag.
Blake, R, \& Logothetis, N. K. (2002). Visual competition. Nature Reviews Neuroscience, 3, 13-21.

Bonneh, Y., SAGI, D., \& Karni, A. (2001). A transition between eye and object rivalry determined by stimulus coherence. Vision Research, 41, 981-989.

CAREY, D. P. (2001). Vision research: Losing sight of eye dominance. Current Biology, 11, R828-R830.

Charnwood, J. R. B. (1954). An answer to the suppression theory. British Orthoptic Journal, 11, 32-37.

Church, J. (1966). Language and the discovery of reality. New York: Vintage.

Ciuffreda, K. J., Levi, D. M., \& Selenow, A. (1992). Amblyopia: Basic and clinical aspects. Boston: Butterworth.

Clark, B. (1936). An eye movement study of stereoscopic vision. American Journal of Psychology, 48, 82-97.

Clark, M. M. (1957). Left-handedness. London: University of London Press.

Coons, J. C., \& Mathias, R. J. (1928). Eye and hand preference tendencies. Journal of Genetic Psychology, 35, 629-632.

Coren, S., \& Duckman, R. H. (1975). Ocular dominance and amblyopia. American Journal of Optometry \& Physiological Optics, 52, 47-50.

Coren, S., \& Kaplan, C. P. (1973). Patterns of ocular dominance. American Journal of Optometry \& Physiological Optics, 50, 283 292.

Coren, S., \& Porac, C. (1975). Ocular dominance: An annotated bibliography. Journal Supplement Abstract Service, Catalog of Selected Documents in Psychology, 5, 229-230.

Crovitz, H. F. (1961). Differential acuity of the two eyes and the problem of ocular dominance. Science, 134, 614.

CufF, N. (1931). A study of eyedness and handedness. Journal of Experimental Psychology, 14, 164-175.

Dengis, C. A., Simpson, T. L., Steinbach, M. J., \& Ono, H. (1998). The cyclops effect in adults: Sighting without visual feedback. $\mathrm{Vi}$ sion Research, 38, 327-331.

Dengis, C. A., Steinbach, M. J., Ono, H., Gunther, L. N., Fanfarillo, R., Steeves, J. K. E., \& Postiglione, S. (1996). Learning to look with one eye: The use of head turn by normals and strabismics. Vision Research, 36, 3237-3242.

Downey, J. E. (1933). Laterality of function. Psychological Bulletin, 30, $109-142$.

Durand, A. C., \& Gould, G. M. (1910). A method of determining ocular dominance. Journal of the American Medical Association, 55, 369-370.

ENRIGHT, J. T. (1992). The remarkable saccades of asymmetrical vergence. Vision Research, 32, 2261-2276.

ERKELENS, C. J. (2000). Perceived direction during monocular viewing is based on signals of the viewing eye only. Vision Research, 40, 2411-2419.

Erkelens, C. J., \& van de Grind, W. A. (1994). Binocular visual direction. Vision Research, 34, 2963-2969.

ERKELENS, C. J., \& VAN Ee, R. (2002). The role of the cyclopean eye in vision: Sometimes inappropriate, always irrelevant. Vision Research, 42, 1157-1163.

FINK, W. H. (1938). The dominant eye: Its clinical significance. Archives of Ophthalmology, 19, 555-582.

Friedlander, W. J. (1971). Some aspects of eyedness. Cortex, 7, $357-$ 371.

GaHAGan, L. (1933). Visual dominance-acuity relationship. Journal of General Psychology, 9, 455-459.

Gronwall, D. M. A., \& Sampson, H. (1971). Ocular dominance: A test of two hypotheses. British Journal of Psychology, 62, 175-185.

Hering, E. (1942). Spatial sense and movements of the eye (C. A. Radde, Trans.). Baltimore: American Academy of Optometry. (Original work published 1879)

Hering, E. (1977). The theory of binocular vision (B. Bridgeman \& L. Stark, Eds.). New York: Plenum. (Original work published 1868)

HiLdreth, G. J. (1949). The development and training of hand dominance. Journal of Genetic Psychology, 75, 221-275.

Holopigian, K., Blake, R., \& Greenwald, M. J. (1988). Clinical suppression and amblyopia. Investigative Ophthalmology \& Visual Science, 29, 444-451. 
Howard, I. P. (1996). Alhazen's neglected discoveries of visual phenomena. Perception, 25, 1203-1217.

Howard, I. P. (2002). Seeing in depth: Vol. 1. Basic mechanisms. Toronto: I. Porteous.

HowARD, I. P., \& Rogers, B. J. (1995). Binocular vision and stereopsis. New York: Oxford University Press.

Howard, I. P., \& Rogers, B. J. (2002). Seeing in depth: Vol. 2. Depth perception. Toronto: I. Porteous.

Howard, I. P., \& WAdE, N. J. (1996). Ptolemy's contributions to the geometry of binocular vision. Perception, 25, 1189-1201.

Khan, A. Z., \& Crawford, J. D. (2001). Ocular dominance reverses as a function of horizontal gaze angle. Vision Research, 41, 1743-1748.

Le Conte, J. (1871). On some phenomena of binocular vision. American Journal of Science, 1, 33-44.

Levelt, W. J. M. (1968). On binocular rivalry. Paris: Mouton.

Levi, D. M. (1991). Spatial vision in amblyopia. In D. Regan (Ed.), Spatial vision (pp. 212-238). Boca Raton, FL: CRC Press.

MAPP, A. P., \& ONO, H. (1999). Wondering about the wandering cyclopean eye. Vision Research, 39, 2381-2386.

MAPP, A. P., ONo, H., \& Howard, I. P. (2002). Binocular visual direction. In I. P. Howard \& B. J. Rogers (Eds.), Seeing in depth: Vol. 2. Depth perception (pp. 85-99). Toronto: I. Porteous.

McManus, I. C., Porac, C., Bryden, M. P., \& Boucher, R. (1999). Eyedominance, writing hand, and throwing hand. Laterality, 4, 173-192.

Menon, R. S., Ogawa, S., Strupp, J. P., \& Ugurbil, K. (1997). Ocular dominance in human V1 demonstrated by functional magnetic resonance imaging. Journal of Neurophysiology, 77, 2780-2787.

Merrell, D. J. (1957). Dominance of eye and hand. Human Biology, 29, 314-328.

Miles, W. R. (1928). Ocular dominance: Methods and results. Psychological Bulletin, 25, 155-156.

Miles, W. R. (1929). Ocular dominance demonstrated by unconscious sighting. Journal of Experimental Psychology, 12, 113-126.

MiLES, W. R. (1930). Ocular dominance in human adults. Journal of General Psychology, 3, 412-430.

MilLs, L. (1925). Eyedness and handedness. American Journal of Ophthalmology, 8 (Series 3), 933-941.

Moiseeva, V. V., Slavutskaya, M. V., \& Shul'govskit, V. V. (2000). The effects of visual stimulation of the dominant and non-dominant eyes on the latent period of saccades and the latency of the peak of rapid pre-saccade potentials. Neuroscience \& Behavioral Physiology, 30, 379-382.

Money, J. (1972). Studies on the functioning of sighting dominance. Quarterly Journal of Experimental Psychology, 24, 454-464.

Ono, H., Angus, R., \& Gregor, P. (1977). Binocular single vision achieved by fusion and suppression. Perception \& Psychophysics, 21, 513-521.

Ono, H., \& Barbeito, R. (1982). The cyclopean eye vs. the sightingdominant eye as the center of visual direction. Perception \& Psychophysics, 32, 201-210.

ONO, H., \& BARBEITO, R. (1985). Utrocular discrimination is not sufficient for utrocular identification. Vision Research, 25, 289-299.

Ono, H., Komoda, M., \& Mueller, E. R. (1971). Intermittent stimulation of binocular disparate colors and central color fusion. Perception \& Psychophysics, 9, 343-347.

Ono, H., Lillakas, L., \& Mapp, A. P. (2003). The making of the direction sensing system for the Howard eggmobile. In L. Harris \& M. Jenkin (Eds.), Levels of perception (pp. 127-147). New York: Springer-Verlag.

Ono, H., Mapp, A. P., \& Howard, I. P. (2002). The cyclopean eye in vision: The new and old data continue to hit you right between the eyes. Vision Research, 42, 1307-1324.

Ono, H., Shimono, K., SAida, S., \& Ujike, H. (2000). Transformation of the visual-line value in binocular vision: Stimuli on corresponding points can be seen in two different directions. Perception, 29, 421-436.

Papousek, I., \& Schulter, G. (1999). Quantitative assessment of five behavioural laterality measures: Distributions of scores and intercorrelations among right-handers. Laterality, 4, 345-362.

Parson, B. S. (1924). Lefthandedness. New York: Macmilllan.
PickWELl, L. D. (1972). Hering's law of equal innervation and the position of the binoculus. Vision Research, 12, 1499-1507.

Pointer, J. S. (2001). Sighting dominance, handedness, and visual acuity preference: Three mutually exclusive modalities? Ophthalmic \& Physiological Optics, 21, 117-126.

Porac, C., \& Coren, S. (1975a). Is eye dominance a part of generalized laterality? Perceptual \& Motor Skills, 40, 763-769.

Porac, C., \& CoREn, S. (1975b). Suppressive processes in binocular vision: Ocular dominance and amblyopia. American Journal of $\mathrm{Op}$ tometry \& Physiological Optics, 52, 651-657.

Porac, C., \& Coren, S. (1976). The dominant eye. Psychological Bulletin, 83, 880-897.

Porac, C., \& CoRen, S. (1981). Lateral preferences and human behavior. New York: Springer-Verlag.

Porac, C., \& Coren, S. (1986). Sighting dominance and egocentric localization. Vision Research, 26, 1709-1713.

Porac, C., Whitford, F. W., \& Coren, S. (1976). The relationship between eye dominance and monocular acuity: An additional consideration. American Journal of Optometry \& Physiological Optics, 53, 803-806.

PorTa, J. B. (1593). De refractione optices parte: Libri novem. Naples: Carlinum \& Pacem.

Rombouts, S. A., Barkhof, F., Sprenger, M., Valk, J., \& Scheltens, P. (1996). The functional basis of ocular dominance: Functional MRI (fMRI) finding. Neuroscience Letters, 221, 1-4.

Rubin, M. L., \& WALLS, G. L. (1969). Fundamentals of visual science. Springfield, IL: Thomas.

SAIDA, S., ONO, H., \& MAPP, A. P. (2001). Closed-loop and open-loop accommodative vergence eye movements. Vision Research, 41, 77-86.

Schoen, Z J., \& Scofield, C. F. (1935). A study of the relative neuromuscular efficiency of the dominant and non-dominant eye in binocular vision. Journal of General Psychology, 11, 156-181.

Schor, C. M. (1977). Visual stimuli for strabismic suppression. Perception, 6, 583-593.

Schröder, J., Fries, P., Roelfsema, P. R., Singer W., \& Engel, A. K. (2002). Ocular dominance in extrastriate cortex of strabismic amblyopic cats. Vision Research, 42, 29-39.

SHEARD, C. (1926). Unilateral sighting and ocular dominance. American Journal of Physiological Optics, 7, 558-567.

Smith, E. L., Levi, D. M., Manny, R. E., Harwerth, R. S., \& White, J. M. (1985). The relationship between binocular rivalry and strabismic suppression. Investigative Ophthalmology \& Visual Science, 29, 80-87.

SNyder, A. M., \& SNyder, M. A. (1928). Eye preference tendencies. Journal of Educational Psychology, 19, 431-433.

Steinbach, M. J., Howard, I. P., \& ONo, H. (1985). Monocular asymmetries in vision: We don't see eye to eye. Canadian Journal of Psychology, 39, 476-478.

van Kruysbergen, N. (1995). Aspects of monocular and binocular motion aftereffects. Unpublished doctoral dissertation, University Press Nijmegen, The Netherlands.

Verhoeff, F. H. (1935). A new theory of binocular vision. Archives of Ophthalmology, 13, 151-175.

VON Noorden, G. K. (1990). Binocular vision and ocular motility. St. Louis: Mosby.

WADE, N. J. (1998). Early studies of eye dominances. Laterality, 3, $97-$ 108.

WaLLS, G. L. (1951). A theory of ocular dominance. Archives of Ophthalmology, 45, 387-412.

Warren, N., \& Clark, B. (1938). A consideration of the use of the term ocular dominance. Psychological Bulletin, 35, 298-304.

Washburn, M. F., FAISON, C., \& Scott, R. (1934). A comparison between the Miles A-B-C method and retinal rivalry as tests of ocular dominance. American Journal of Psychology, 46, 633-636.

Wells, W. C. (1792). An essay upon single vision with two eyes: Together with experiments and observations on several other subjects in optics. London: Cadell.

White, M. J. (1969). Laterality differences in perception: A review. Psychological Bulletin, 72, 387-405. 
Wolfe, J. M. (1983). Afterimages binocular rivalry and the temporal properties of dominance and suppression. Perception, 12, 439-445.

Wolfe, J. M. (1986a). Briefly presented stimuli can disrupt constant suppression and binocular rivalry suppression. Perception, 15, 413417.

Wolfe, J. M. (1986b). Stereopsis and binocular rivalry. Psychological Review, 93, 269-282.

\section{NOTES}

1. There is an issue in the binocular rivalry literature as to "what rivals during rivalry?" Specifically, the issue is whether the early or the late stages of processing are responsible for what one sees. Sometimes the early stage process is identified as a competition between the two eyes, but the competition considered in this context is what we refer to above as the stimulus factor. That is, the variables considered are contrast, contour, or time and they are thought to be processed earlier than the "high-level" variables (see Blake, 2003; Bonneh, Sagi, \& Karni, 2001).
2. Recently, Erkelens (2000) and Erkelens and van Ee (2002) challenged the idea that the two eyes function as a single organ. For a rebuttal, however, see Ono, Mapp, and Howard (2002) and Ono, Lillakas, and Mapp (2003). The argument of Erkelens and of Erkelens and van Ee is similar to that of Khan and Crawford (2001) in that a proposal is made that information from only one eye is used. Among other things, both proposals must address how the eye-of-origin information is discarded by the visual system and is not available to consciousness (for discussions, see, e.g., Ono \& Barbeito, 1985; Steinbach, Howard, \& Ono, 1985), even for observers with one normal and one amblyopic eye (Barbeito, Levi, Klein, Loshin, \& Ono, 1985).

3 . The experiment described as a thought experiment in the text was actually conducted using 15 participants, and our predicted results were confirmed. To shorten this paper, however, we do not describe the experiment in detail.

(Manuscript received November 12, 2001; revision accepted for publication September 3, 2002.) 